\title{
SOCIAL ROBOTS, CROSS-CULTURAL DIFFERENCES
}

\author{
Ana R. Delgado, Margarita G. Marquez \\ Psicología Básica, Psicobiología y Metodología. Universidad de Salamanca. Salamanca, Spain. \\ adelgado@usal.es,.mgmarquez@usal.es
}

Keywords: $\quad$ anger, contempt, cross-cultural differences, disgust, moral emotions, social robots.

\begin{abstract}
The study of emotion abilities is of interest to Artificial Intelligence because identifying and responding appropriately to the affective states of humans is thought to make users more prone to interact with robots. However, cross-cultural differences in social communication are common. The CAD (Contempt, Anger, Disgust) hypothesis proposes that these three emotions are elicited by different violations of moral codes. Our exploratory study of texts from a corpus of Spanish contextualized words shows that both the emotion receiver and its perceived cause are different for these emotions: disgust takes as its object mostly something concrete, anger is preferentially felt towards another person, and contempt towards an abstract object. In Spain, disgust was associated with prejudice, and anger with altruistic motives while contempt remained the most elusive of the triad. In Latin America, both disgust and contempt were associated with prejudice, while the altruistic function of anger failed to reach significance. Differences concerning the moral functions of anger and contempt corroborate that the cultural context in which emotions are expressed can change their moral meaning. The procedure is an ecologically valid one that can be of help for designing more realistic social robots.
\end{abstract}

\section{INTRODUCTION}

In Robotics, emotional skills are assumed as convenient: recognizing and responding to the affective states of humans is thought to make users more prone to interact with robots (Cañamero, 2005). The affective revolution in Psychology is producing enough knowledge to help engineers to decide the "best" emotion for different human-robot interaction situations by taking into account the evolutionary roots of emotions as well as the functionality of each one of them in the current interaction contexts (Delgado, 2009a).

Affects are playing an increasing role in the newest theories of morality (Bloom, 2010; Haidt, 2008). This approach is partly related to the spread of evolutionary psychology in which the origins of morality are related to reciprocal altruism (Cosmides \& Tooby, 2005). The CAD (Contempt, Anger, Disgust) hypothesis, proposes that these emotions have distinct moral functions, i.e., would be elicited by violations of different codes (Rozin, Lowery, Imada \& Haidt, 1999). Rozin, Haidt and Fincher (2009) have recently analyzed how core disgust, which originates in the mammalian bitter taste rejection system, became true disgust when the eliciting category was enlarged to include a disgust evaluation system that responded to more cognitively elaborated appraisals and, later on, to social stimuli. Moral offences would be a further extension of the disgust evaluation system. However, empirical evidence indicates that disgust may also be elicited by violations of the autonomy code, which according to the CAD hypothesis would be associated with anger (Rozin, Lowery, Imada \& Haidt, 1999). The fact that some moral transgressions trigger the same facial motor activity that is evoked by distasteful and basic disgust items (Chapman, Kim, Susskind \& Anderson, 2009) is a weak corroboration of the "from oral to moral" disgust exaptation hypothesis because it is compatible with alternative views (Rozin, Haidt \& Fincher, 2009).

As to appraisals or attributions, both reciprocal and altruistic scenarios are currently considered in the scope of moral psychology (Cosmides \& Tooby, 2005; Haidt, 2008). In this sense, results linking disgust to prejudice indicate that the usual role of disgust is not the moral one (Taylor, 2007) and, apart from some isolated observations, ecological evidence for the ethical role of contempt is lacking. 
From a methodological point of view, moral psychology has been criticized for focusing nearly exclusively on studies in which volunteers solve artificial moral dilemmas imagined by other people (Bloom, 2010). The lack of stimulus representativeness makes generalization to everyday life problematic (Baumard \& Sperber, 2010; Delgado, 2009b).

Analyzing representative text corpora allows the researcher to avoid the previous critiques because words can be observed unobtrusively (Bauer \& Aarts, 2000; Webb, Campbell, Schwartz, Sechrest \& Grove, 1981). A clear limitation of qualitative text analysis is subjectivity, which can be somewhat controlled by indirect means, but never eliminated. In contrast, a clear advantage of this procedure is that if the text corpus is not in English then the limitation that researchers might be imposing concepts from English vocabularies on participants is avoided. Thus our objective was to show the distinct functions of contempt, anger, and disgust on ecologically valid data: contextualized Spanish words for these three emotions. The first part of this study was carried out on the Spanish of Spain and had a descriptive objective; the second part, on the Spanish of Latin America, had comparison as its objective.

\section{METHOD}

\subsection{Samples}

This study was carried out on the Current Spanish Reference Corpus, a stratified sample of contextualized Spanish words from 1975 to 2004 (RAE, 2010). It is composed of more than $150,000,000$ words and has been designed to offer a representative sample of standard Spanish from 1975-2004. Criteria for text inclusion are clearly specified: $50 \%$ from Spain, and 50\% from America (Mexican, Central, Caribbean, Andean, Chilean, and River Plate area); $90 \%$ written, and $10 \%$ oral. Various topics have been sampled: Science and Technology, Social Sciences, Politics and Economics, Arts, Health, Fiction, Leisure and Everyday life. The first working corpus was composed of every document (from Spain) including the Spanish nouns for contempt, anger or disgust (i.e., desprecio, rabia and asco). Note that this corpus includes sayings and other expressions that are not objectively comparable to heteroattributional scenarios, in which emotions are predicated on somebody else. Only 362 texts were finally selected: the heteroattributional ones on whose coding two "blind" observers had perfectly agreed. Of these, some 141 texts corresponded to contempt, 124 to anger and 97 to disgust. Our assumption was that stringent criteria (i.e., perfect agreement on object and attribution codes) would leave the noise in the data out of the analysis, allowing the emergence of clear association patterns. The second part of the study was carried out on 139 texts from Latin America: the heteroattributional ones on whose coding two "blind" observers perfectly agreed. The original working corpus for this comparative study was composed of every document (from the three largest Latin American Spanish-speaking zones) including the Spanish nouns for contempt, anger or disgust. Of these, 46 belonged to Argentina, 33 to Chile and 60 to Mexico. It has been found that these three Latin American countries differ in values from Spain (Schwartz, 2008).

\subsection{Procedure}

The exhaustive and mutually exclusive category systems were developed in two phases: (1) inductive text categorization by a researcher blind to the CAD hypothesis, and (2) deductive refining of the categories to take into account theoretical codes from previous research (Delgado, 2009a). Emotion receivers and attributions were salient in most texts and therefore these two structural elements associated with social communication led to two concurrent category systems. Finally two "blind" observers, carefully selected for their excellent grades (a procedure that warrants the high level of reading comprehension that is needed for the task), independently read and coded the texts following instructions concerning the receiver and attribution categories developed in the bottom-up part of this study. Data were then quantitatively analyzed. Various categories and subcategories were eliminated from the analyses due to low frequencies and/or agreement problems. The second part of the study was carried out on the Spanish of Latin America with the refined category systems. Two new "blind" observers independently read and coded the texts. Data were then quantitatively analyzed and results compared with those from the Spanish of Spain.

\section{RESULTS}

Results from the 362 selected texts indicate that, in 
Spain, the typical emotion receiver is different for contempt, anger and disgust scenarios, $\chi^{2}(6)=$ 108.33, Cramer's $V=.39, p<.001$. Standardized residuals from Table 1 show that, while disgust takes as its object mostly something concrete (e.g., feces, bad breath), anger is preferentially felt towards another person, and contempt towards an abstract object such as terrorism or a social institution. The category "oneself", which was initially part of the coding system, contained only seven cases and had to be collapsed with the category "non-explicit or other" given that $\chi^{2}$ tests are not recommended when expected frequencies are too low. In any case, the CAD hypothesis proposes contempt, anger and disgust as other-rejecting emotions.

Table 1. Number (corrected standardized residual) of receiver categories by emotion in Spain.

\begin{tabular}{llll}
\hline & Contempt & Anger & Disgust \\
Concrete object & 3 & 5 & 44 \\
& $(-5.3)$ & $(-4.0)$ & $(10.2)$ \\
Person & 83 & 78 & 28 \\
& $(2.0)$ & $(2.9)$ & $(-5.4)$ \\
Abstract object & 46 & 29 & 20 \\
& $(2.2)$ & $(-0.9)$ & $(-1.5)$ \\
Non-explicit/ other & 9 & 12 & 5 \\
& $(-0.5)$ & $(1.3)$ & $(-0.9)$ \\
\hline
\end{tabular}

Following current theorization on morality, Table 2 attribution labels correspond to the coded motives as follows: prejudice is used when the cause of the emotion is "something negative that is intrinsic to the object or person receiving the emotion"; reciprocal is used when the cause of the emotion is "something negative that the emotion receiver has done to the person feeling the emotion"; and the label altruistic is used when the cause of the emotion is "something negative that the emotion receiver has done to a third party".

Table 2. Number (corrected standardized residual) of attribution categories by emotion in Spain.

\begin{tabular}{llll}
\hline & Contempt & Anger & Disgust \\
Prejudice & 87 & 42 & 83 \\
& $(1.0)$ & $(-6.9)$ & $(6.3)$ \\
Reciprocal & 25 & 41 & 7 \\
& $(-.9)$ & $(4.4)$ & $(-3.7)$ \\
Altruistic & 0 & 26 & 2 \\
& $(-4.4)$ & $(6.8)$ & $(-2.4)$ \\
Non-explicit/ other & 29 & 15 & 5 \\
& $(3.1)$ & $(-0.6)$ & $(-2.8)$ \\
\hline
\end{tabular}

Table 2 shows that the moral function of the CAD emotions is present in our data: some reciprocal attributions are found for anger, contempt and disgust (in descending order), as well as altruistic motives for anger and, in two texts, for disgust. It can also be seen that significant differences between contempt, anger and disgust can be found concerning attributions, $\chi^{2}(6)=97.32$, Cramer's $V=.37, p<.001$. Standardized residuals indicate that disgust is positively associated with prejudice, while anger is positively associated both with reciprocity and altruism, the moral contexts. As for contempt, there is only one large positive adjusted standardized residual due to the twentynine texts in the "non-explicit or other" category.

As to the comparative part of this study, results from the 139 selected texts show that, in Latin America, the typical emotion receiver is different for contempt, anger and disgust scenarios (see Table 3), closely replicating results from Spain, $\chi^{2}(6)=64,35$, Cramer's $V=.48, p<.001$.

Table 3. Number (corrected standardized residual) of receiver categories by emotion in Latin America.

\begin{tabular}{llll}
\hline & Contempt & Anger & Disgust \\
Concrete object & 5 & 2 & 15 \\
& $(-1.9)$ & $(-3.4)$ & $(6.9)$ \\
Person & 32 & 44 & 5 \\
& $(-0.4)$ & $(3.6)$ & $(-4.1)$ \\
Abstract object & 18 & 4 & 2 \\
Non-explicit/ other & $(3.7)$ & $(-2.7)$ & $(-1.3)$ \\
& 2 & 8 & 2 \\
& $(-1.8)$ & $(1.8)$ & $(-0.1)$ \\
\hline
\end{tabular}

Table 4 shows that the moral function of the CAD emotions is somewhat different in Latin America: both reciprocal and altruistic attributions are found for anger, contempt and disgust (in descending order), and there is a significant association between emotions and attributions, $\chi^{2}$ $(6)=49,15$, Cramer's $V=.42, p<.001$, but residual analyses show that contempt is associated with prejudice, and that the altruistic function of anger fails to reach significance. The association of disgust with prejudice and anger with (lack of) reciprocity did replicate results from Spain.

Table 4. Number (corrected standardized residual) of attribution categories by emotion in Latin America.

\begin{tabular}{lclc}
\hline & Contempt & Anger & Disgust \\
Prejudice & 32 & 5 & 19 \\
& $(3.2)$ & $(-6.4)$ & $(4.3)$ \\
Reciprocal & 14 & 35 & 1 \\
& $(-2.3)$ & $(5.1)$ & $(-3.6)$ \\
Altruistic & 2 & 7 & 1 \\
& $(-1.4)$ & $(1.9)$ & $(-.6)$ \\
Non-explicit/ other & 9 & 11 & 3 \\
& $(-.2)$ & $(.6)$ & $(-.6)$ \\
\hline
\end{tabular}




\section{CONCLUSIONS}

In the descriptive part of this study, our analysis of 362 texts from a representative corpus of contextualized words from Spain corroborates the existence of a number of moral functions of contempt, anger and disgust in everyday life, and shows that both the emotion receiver and its perceived cause are different for these emotions: disgust is mostly associated with concrete objects, anger with persons, and contempt with abstract objects.

Concerning attributions, disgust is mostly associated with what we have denominated prejudice (i.e., due to something negative that is intrinsic to the object or person receiving the emotion) and anger with what we have called reciprocal and altruistic motives, while contempt remains the most elusive of the emotion triad. The moral role of contempt, the most salient of the CAD emotions in Spain (Delgado, 2009b), was limited to a number of reciprocal scenarios; the fact that there are twenty-nine contempt texts in the "non-explicit or other" category indicates that attributions for contempt are the most subtle, and thus the most difficult to categorize.

In the comparative part of the study, results from Latin America replicated results from Spain concerning the emotion receivers. The association of disgust with prejudice and anger with (lack of) reciprocity were again found. However, contrary to expectations, the altruistic function of anger did not reach significance and contempt was associated with prejudice.

With respect to the CAD emotions, some cross-cultural differences have already been reported: Americans have been found to endorse contempt and disgust expressions more often than Germans, who endorsed anger more (KoopmannHolm \& Matsumoto, 2011). Differences concerning the moral functions of contempt in Spain and Latin America go a step further by showing some differences in meaning when language is the same. Given differences in values between Latin American countries and Spain (Schwartz, 2008), our results could be explained by resorting to value-related constructs. Our procedure is an ecologically valid one that can be of help for designing more realistic social robots.

\section{ACKNOWLEDGEMENTS}

This research was partially supported by research grants MEC EXPLORA SEJ2007-29492-E and
MICINN PSI2009-09490. The authors wish to thank Sergio de Dios and Angel Sanchez-Rodriguez for acting as blind coders for the first part of this study and Carlota Calvo and Marta Montero for acting as blind coders for the second part.

\section{REFERENCES}

Bauer, M. W., Aarts, B., 2000. Corpus construction: a principle for qualitative data collection. In M.W. Bauer and G. Gaskell (Eds.), Qualitative researching with text, image and sound. A practical handbook (pp.19-37). London: Sage.

Baumard, N., Sperber, D., 2010. Weird people, yes, but also weird experiments. Behavioral and Brain Sciences, 33, 84-85.

Bloom, P., 2010. How do morals change? Nature, 464.

Cañamero, L., 2005. Emotion understanding from the perspective of autonomous robots research. Neural Networks, 18, 445-455.

Chapman, H.A., Kim, D.A., Susskind, J.M., Anderson, A.K., 2009. In bad taste: evidence for the oral origins of moral disgust. Science, 323, 1222-1226.

Cosmides, L., Tooby, J., 2005. Neurocognitive adaptations designed for social exchange. In D. M. Buss (Ed.), Evolutionary psychology Handbook (pp. 548-627). New York: Wiley.

Delgado, A. R., 2009a. Social Robots, Moral Emotions. Proceedings of the 11th International Conference on Enterprise Information Systems (pp. 263-270). INSTICC.

Delgado, A.R., 2009b. Spanish basic emotion words are consistently ordered. Quality \& Quantity, 43, 509-517.

Haidt, J. (2008). Morality. Perspectives on Psychological Science, 3, 65-72.

Koopmann-Holm, B., Matsumoto, D., 2011. Values and display rules for specific emotions. Journal of CrossCultural Psychology, 42, 355-371.

Moll, J., de Oliveira-Souza, R., Zahn, R., 2008. The neural basis of moral cognition. Sentiments, concepts, and values. Annals of the New York Academy of Sciences, 1124, 161-180.

Real Academia Española, 2010. Spanish Royal Academy Data Bank (CREA) [on-line]. Corpus de referencia del español actual. $<$ http://www.rae.es $>$

Rozin, P., Haidt, J., Fincher, K., 2009. From oral to moral. Science, 323, 1179-1180

Rozin, P., Lowery, L., Imada, S., Haidt, J., 1999. The CAD triad hypothesis: A mapping between three moral emotions (contempt, anger, disgust) and three moral codes (community, autonomy, divinity). Journal of Personality and Social Psychology, 76, 574-586.

Schwartz, S. H., 2008. Cultural value orientations: Nature and implications of national differences. Moscow: State University Higher School of Economics Press.

Taylor, K., 2007. Disgust is a factor in extreme prejudice. British Journal of Social Psychology, 46, 597-617. 